\title{
AIRWAY CLOSURE AND LUNG VOLUMES IN SURGICAL POSITIONS
}

\author{
Douglas B. Craig, M.D., W. M. Wahba, M.D., and Hillary Don, F.R.C.P.(c)*
}

The Closure of SMALL AIRWAYs in dependent lung zones of normal subjects has been described by a number of authors. Indirect evidence for airway closure has been provided by Milic-Emili and his colleagues using ${ }^{133} \mathrm{Xenon},{ }^{1,2}$ by Anthonisen using a modified single breath nitrogen technique, ${ }^{3}$ and by Jones and Clarke using argon or nitrogen boluses. ${ }^{4}$ Burger and Macklem $^{5}$ demonstrated gas trapping behind closed airways in normal subjects, and Hughes has shown histological evidence of small airway closure in excised perfused dog lungs. ${ }^{6}$

Airway closure is thought to occur when the net forces acting on small airways are such as to induce their collapse. The identification of an intrapleural pressure gradient, with pressures approaching or exceeding zero in gravity dependent zones $^{7}$ explains the origin of the factors promoting closure. Elastic forces in the pulmonary parenchyma, and properties of the airways themselves are seen as opposing closure. Decreasing elastic recoil and loss of airway integrity in the aging lung, with therefore less opposition to airway collapse, explains the observation of increased airway closure with age..$^{3,8}$

The functional consequence of airway closure is thought to be an impairment of the ventilation to affected lung regions with a resultant lowering of ventilationperfusion ( $\mathrm{v} / \mathrm{Q}$ ) ratios, such as to adversely affect pulmonary gas exchange. In addition, gas trapped behind closed airways can, in some circumstances, become absorbed, producing atelectasis, ${ }^{5}$ and thereby further impairing gas exchange.

Although this phenomenon has received little attention in the anaesthetic literature, it likely has major functional significance in patients during anaesthesia, and in the pre- and post-operative periods.

Leblanc, Ruff and Milic-Emili ${ }^{8}$ have shown important alterations in the relationship of airway closure to functional residual capacity associated with the change from the seated to the supine position. In the present study the effect of several surgical positions on airway closure and lung volumes was examined, with the aim of demonstrating some of the factors that might be of significance to the anaesthetic and peri-operative states.

\section{METHODS}

Ten normal male physicians, aged 28 to 53 years were studied. Their biometric data, and seated pulmonary function values are included in Table I. All subjects

*Dr. Craig and Dr. Wahba are Research Fellows and Hillary Don is Associate Professor in the Department of Anaesthesia, Royal Victoria Hospital and McGill University, Montreal, Quebec, Canada.

Supported by the Medical Research Council of Canada.

Address communications to: Dr. D. B. Craig, Department of Anaesthesia, Winnipeg General Hospital, Winnipeg, Manitoba. 


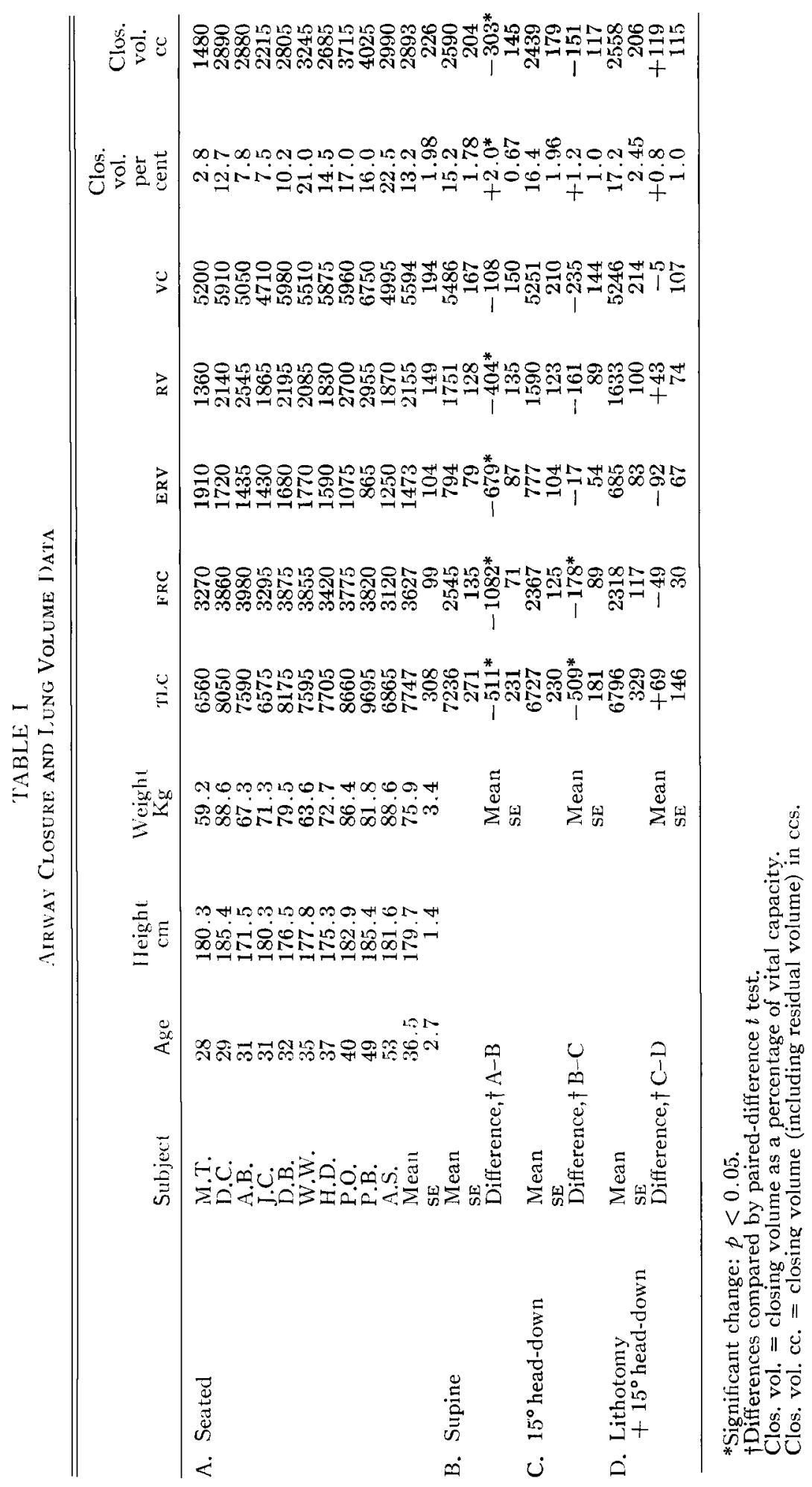


were studied in the same postural sequence, with a minimum of five minutes in each position before measurements were begun. The positions investigated were the seated, supine, supine with $15^{\circ}$ head down (legs remaining straight), and the lithotomy plus $15^{\circ}$ head down. In the lithotomy position the hips were flexed so that the thighs made an angle of approximately $80^{\circ}$ with the trunk.

\section{Lung volumes}

Functional residual capacity (FRC) was measured by the closed-circuit helium technique using a catharometer (Cambridge Instrument Company) for helium analysis. Following helium equilibration, the expiratory reserve volume (ERV) and inspiratory capacity (Ic) were measured using the same apparatus. All volumes reported have been corrected to body temperature, atmospheric pressure, and water vapour saturated conditions (BTPS).

\section{Airway closure}

A modified single breath nitrogen technique, similar to that described by Anthonisen $^{3}$ was used to evaluate airway closure. Subjects exhaled to residual volume (Rv), were switched into an oxygen filled closed circuit system, and inspired a vital capacity (vc) breath of oxygen from a Wedge spirometer (Model 170, Med-Science Electronics, St. Louis, Missouri). This manoeuvre is known to accentuate regional differences in nitrogen concentration in the lung, with superior lung regions having a higher concentration than do gravity-dependent regions. ${ }^{3}$ Following a 10-second breath hold, subjects exhaled slowly and evenly over approximately 10 seconds, to Rv. Gas was sampled at the mouth and analysed for nitrogen (Vertek VR 3400 Nitrogen Analyzer, Burlington, Vermont). The volume signal from the Wedge spirometer was displayed on the $\mathrm{X}$-axis, nitrogen concentration on the Y-axis of an X-Y recorder (Hewlett-Packard 7035B). An example of the tracings produced is seen in Figure 1. The expired gas tracing can be divided into four phases, as previously described. ${ }^{1}$ Nitrogen-free dead space gas forms Phase I, followed by Phase $\Pi$, the transition from dead space to alveolar gas. The classical alveolar plateau, with its cardiogenic oscillations, forms Phase III. The terminal portion of this plateau, with its changed slope, has been termed Phase Iv by Dollfuss. ${ }^{1}$ The junction between Phase III and Phase IV is interpreted as showing the point of onset of airway closure, ${ }^{3}$ and this volume is termed the closing volume. This volume is reported in Table I as a percentage of vc, and also as an absolute lung volume, including Rv. The closing volumes reported represent the means of at least two manoeuvres in each position.

\section{RESULtS}

The lung volume and airway closure results are summarized in Table I. Complete data for the seated position is followed by mean values for the subsequent three positions. The mean values are also given for the differences between each position and the one immediately preceding it. All the lung volumes except the vital capacity decreased significantly with the change from sitting to supine. With the subsequent addition of the $15^{\circ}$ head down position, only the total lung capa- 




FigLre 1. Concentration of nitrogen in expired gas (per cent $\mathrm{N}_{2}$ ), measured at the mouth, as a function of expired volume, in per cent vital capacity (per cent vc). See text for description of phases.


Frgure 2. Relationship of the differences between functional residual capacity (FRC) and closing volume, to subjects' ages, in the four positions. Dashed lines obtained by regression analysis; see text for explanation. 
city and functional residual capacity showed significant changes. The further addition of the lithotomy position was not associated with any significant changes in the parameters studied.

Figure 2 illustrates, for the four positions, the relationship of the difference between FRC and closing volume, to age. The horizontal solid line in each quadrant represents the point where the closing volume is equal to the FRC. Points lying above this line indicate a closing volume less than FRC, while points below it indicate the volume by which closing volume exceeds FRC. In the latter situation airway closure is occurring within the tidal volume range, and functional consequences, as discussed above, would be expected. The dashed lines in each quadrant were obtained by regression analysis, and have the following characteristics:

Seated: FrC-closing volume $=2974-61$ (age); $\mathrm{R}=-0.87 ; p<0.01$

Supine: FRC-closing volume $=1681-47$ (age); $\mathrm{R}=-0.78 ; p<0.01$

Supine $+15^{\circ}$ head-down: Frc-closing volume $=2049-58$ (age);

$\mathrm{R}=-0.86 ; p<0.01$

Lithotomy $+15^{\circ}$ head-down: FRC-closing volume $=1784-55$ (age);

$\mathrm{R}=-0.74 ; p<0.01$

(FRC-closing volume is plotted in Figure 2 in litres, and expressed above in millilitres.)

The point of interception of the dashed regression line represents the age, for this group of subjects, at which airway closure starts to occur within the tidal volume range. This age has been termed the "critical age" by Leblanc et al. ${ }^{8}$ Body position clearly affects the "critical age," which was approximately 49 in the seated position, 36 supine, 35.5 head-down, and 32 in the combined lithotomy and headdown position.

\section{Discussion}

The lung volume changes noted between the seated and supine positions are similar in direction and magnitude to previous reports. ${ }^{9,10,11}$ The large drop in FRC in the supine position is particularly important in relation to the airway closure phenomenon. The supine closing volume decreased slightly, but with the large fall in FRC, airway closure is now seen to occur within tidal volume in five of the ten subjects whereas in the seated posture this was seen in only one subject. The small but statistically significant decrease in FRC between the supine and $15^{\circ}$ head-down position also matches previous experience. ${ }^{9,10,11}$ Earlier studies of FRC in the head-down position have found larger decreases from supine values than seen in this series, but a $25^{\circ}$ or $30^{\circ}$ angle was used. The $15^{\circ}$ angle was used in this study because it was felt to be more in keeping with current clinical usage of the head-down position during anaesthesia and surgery.

The clinical importance of airway closure has already been outlined. Pulmonary gas exchange is likely to be impaired in those subjects in whom closure occurs within the tidal volume range. Figure 2 indicates the effect of posture changes in leading to the shifting of the closing volume to within tidal volume. A further drop in FRC in any position, as has been observed following the induction of 
general anaesthesia ${ }^{12,13}$ would cause airway closure to assume further functional importance. Evidence that airway closure and gas trapping do, in fact, occur during anaesthesia has been provided by Couture. ${ }^{14}$

The appreciation that airway closure is a phenomenon occurring in the lungs of normal subjects invites the re-examination of several existing concepts. It has long been appreciated that breathing at low lung volumes (low FRC) secondary to obesity, ${ }^{15}$ pain ${ }^{16}$ or during general anaesthesia, ${ }^{12,13}$ may be associated with deficient pulmonary gas exchange. Atelectasis has been suggested as the likely mechanism affecting gas exchange, although supporting evidence for this diagnosis has often been lacking. Atelectasis can clearly cause the defects noted in these situations, but airway closure rates consideration as either the sole mechanism responsible, or as perhaps a primary mechanism which then leads to secondary atelectasis.

The reports in the literature have, to date, implied rather than demonstrated functional derangements due to the closure of small airways. The authors have examined this problem in twenty-two subjects aged 21 to 78 years, and have found a significant correlation between airway closure and impairment of pulmonary gas exchange..$^{17}$

It appears that airway closure is a mechanism producing important effects on gas exchange. The role of posture, as explored in this study, and the demonstration of atelectasis following airway closure ${ }^{5}$ provide significant added implications for the anaesthetic and peri-operative periods.

\section{SUMMARY}

The closure of small airways in gravity-dependent lung regions (airway closure) is thought to be an important factor influencing ventilation-perfusion ( $\mathrm{v} / \mathrm{Q}$ ) relationships. Airway closure has been noted by other authors as predisposing to atelectasis, under appropriate circumstances.

We have assessed airway closure by a modified single breath nitrogen technique in ten normal male subjects in several surgical positions. Functional residual capacity (FRC) was measured by a closed-circuit helium technique, to allow correlation of the airway closure findings with the alterations in lung volume associated with the posture changes. Functional consequences of airway closure are likely when the closing volume (the lung volume at which airway closure starts to occur) is above FRC, with closure then occurring within the range of tidal breathing. Subjects were studied in the seated, supine, $15^{\circ}$ head-down, and combined lithotomy plus $15^{\circ}$ head-down positions.

Airway closure was found to involve increasing lung volumes with increasing subjects' ages, in agreement with previous observations. In the seated position the age at which the closing volume exceeded FRC was 49 years. This age decreased to 36 in the supine position, 35.5 head-down, and 32 in the combined lithotomy and head-down position. Body position, therefore, has an important effect on the critical relationship between the closing volume and FRC, and hence on the functional consequences of airway closure. 


\section{ACKNOWLEDGEMENT}

The authors wish to thank Professor M. R. Stephens of the Department of Mathematics, McGill University, who performed the statistical analyses.

\section{RÉSUMÉ}

La fermeture des voies aériennes dans les régions pulmonaires en position déclive (fermeture des bronchioles) est, dit-on, un facteur important influençant la relation ventilation/perfusion v/Q. La fermeture des voies aériennes, au dire d'autres auteurs, prédispose à l'atélectasie dans certaines circonstances.

Chez dix sujets mâles normaux, placés en diverses positions chirurgicales, nous avons évalué la fermeture des voies aériennes par une technique modifiée d'une seule respiration d'azote. Nous avons mesuré la capacité fonctionnelle résiduelle (CFR) par une technique à circuit fermé avec hélium afin de permettre d'établir une correlation entre les résultats obtenus de la fermeture des voies aériennes et les modifications du volume pulmonaire attribuables aux changements de position. Les conséquences fonctionnelles de la fermeture des voies aériennes surviennent lorsque le volume de fermeture dépasse la CFr (le volume pulmonaire auquel commence la fermeture des voies aériennes) alors que la fermeture apparaissant est de l'ordre de l'air courant. Nous avons étudié les sujets en position assise, couchée, la tête baissé de $15^{\circ}$ et la position de lithotomie associée à un Trendelenbourg de $15^{\circ}$.

En accord avec des observations antérieures, la fermeture des voies aériennes s'est étendue à des surfaces pulmonaires augmentant avec lâge des sujets. En position assise, l'âge auquel la fermeture des voies aériennes dépassait la CFr était de 49 ans. En position dorsale, l'âge s'abaissait à 36 ans, en Trendelenbourg, à 35.5 et dans la position associée Trendelenbourg et lithotomie, à 32 ans. En conséquence, la position du corps joue un rôle important sur la relation critique entre la fermeture des voies aériennes et la CFR et, de là sur les conséquences fonctionnelles de la fermeture des voies aériennes.

\section{REFERENCES}

1. Dollfuss, R. E.; Milic-Emir., J.; \& Bates, D. V. Regional Ventilation of the Lung, Studied with Boluses of 133Xenon. Respiration Physiol. 2: 234 (1967).

2. Holland, J.; Mitic-Emit, J.; Macklem, P. T.; \& Bates, D. V. Regional Distribution of Pulmonary Ventilation and Perfusion in Elderly Subjects. J. Clin. Invest. 47: 81 (1968).

3. Anthonisen, N. R.; Danson, J.; Robertson, P. C.; \& Ross, W. D. R. Airway Closure as a Function of Age. Respiration Physiol. 8: 58 (1969).

4. Clarke, S. W.; Jones, J. G.; \& Glaister, D. H. Change in Pulmonary Ventilation in Different Postures, Clin. Sci. 37: 357 (1969).

5. Burger, E. J. Jr.; \& MACknem, P. Airway Closure: Demonstration by Breathing 100 per cent $\mathrm{O}_{2}$ at Low Lung Volumes and by $\mathrm{N}_{2}$ Washout. J. Appl. Physiol. 25: 139 (1968).

6. Hughes, J. M. B.; Rosenzweig, D. Y.; \& Krvitz, P. B. Site and Determinants of Airway Closure in Perfused Dog Lungs (Abstract). Amer. Rev. Resp. Dis. 101: 455 (1970).

7. Milic-Emili, J.; Henderson, J. A. M.; Dolovich, M. B.; Trop, D.; \& Kaneko, K. Regional Distribution of Inspired Gas in the Lung. J. Appl. Physiol. 21: 749 (1966).

8. Leblanc, R.; Ruff, F.; \& Milic-Emili, J. Effects of Age and Body Position on Airway Closure in Man. J. Appl. Physiol. 28: 448 (1970). 
9. Briscoe, W. A. Lung Volumes. In Handbook of Physiology, Section 3, Respiration Volume II, ed. by W. O. Fenn and H. Rahn. Washington, DC, American Physiological Society, 1965, Chap. 53, p. 1345.

10. Agostoni, E.; \& Mead, J. Posture and Lung Volumes. In Handbook of Physiology, Section 3, Respiration Volume $\mathrm{x}$, ed. by W. O. Fenn and H. Rahn, Washington, DC, American Physiological Society, 1964, Chap. 13, p. 387.

11. Blair, E.; \& Hickman, J. B. The Effect of Change in Body Position on Lung Volumes and Intrapulmonary Gas Mixing in Normal Subjects. J. Clin. Invest. 34: 383 (1955).

12. LAwS, A. K. Effects of Induction of Anaesthesia and Muscle Paralysis on Functional Residual Capacity of the Lungs. Canad. Anaesth. Soc. J. 15: 325 (1968).

13. Don, H. F.; Wahba, M.; Cunadrado, L.; \& Kelkar, K. The Effects of Anesthesia and 100 per cent Oxygen on the Functional Residual Capacity of the Lungs. Anesthesiology. (1970). In press.

14. Couture, J.; Picken, J.; Trop, D.; Ruff, F.; Lousada, N.; Houseley, E.; \& Bates, D. V. Airway Closure in Normal, Obese, and Anesthetized Supine Subjects. (Abstract). Federation Proc. 29: 269abs (1970).

15. Bates, D. V.; \& Christie, R. V. Respiratory Function in Disease. An Introduction to the Integrated Study of the Lung. 1st ed. Philadelphia \& London. Saunders, 1964. pp. 103105 .

16. Anscombe, A. R. Pulmonary Complications of Abdominal Surgery. 1st ed. London, LloydLuke (Medical Books), 1957. Chap. vu.

17. Craig, D. B.; Wahba, W. M.; Don, H. F.; \& Becklake, M. R. Effects of Posture on Airway Closure and Pulmonary Gas Exchange. In preparation. 